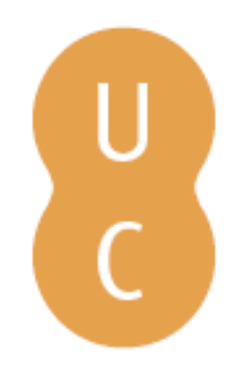

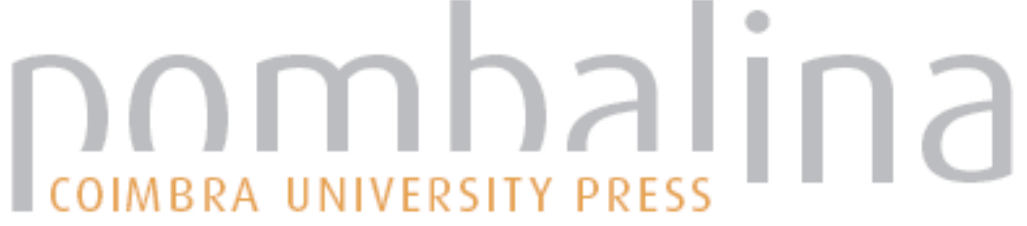

\section{Coesão territorial e governança: abordagem multi-escalar}

Autor(es): $\quad$ Pereira, Margarida; Carranca, Maria Adelaide

Publicado por: Imprensa da Universidade de Coimbra

URL

persistente:

URI:http://hdl.handle.net/10316.2/30829

DOI:

DOI:http://dx.doi.org/10.14195/978-989-26-0244-8_46

Accessed : $\quad$ 26-Apr-2023 15:46:14

A navegação consulta e descarregamento dos títulos inseridos nas Bibliotecas Digitais UC Digitalis, UC Pombalina e UC Impactum, pressupõem a aceitação plena e sem reservas dos Termos e Condições de Uso destas Bibliotecas Digitais, disponíveis em https://digitalis.uc.pt/pt-pt/termos.

Conforme exposto nos referidos Termos e Condições de Uso, o descarregamento de títulos de acesso restrito requer uma licença válida de autorização devendo o utilizador aceder ao(s) documento(s) a partir de um endereço de IP da instituição detentora da supramencionada licença.

Ao utilizador é apenas permitido o descarregamento para uso pessoal, pelo que o emprego do(s) título(s) descarregado(s) para outro fim, designadamente comercial, carece de autorização do respetivo autor ou editor da obra.

Na medida em que todas as obras da UC Digitalis se encontram protegidas pelo Código do Direito de Autor e Direitos Conexos e demais legislação aplicável, toda a cópia, parcial ou total, deste documento, nos casos em que é legalmente admitida, deverá conter ou fazer-se acompanhar por este aviso. 


\section{TRUNFOS DE UMA}

\section{EOGRAFIA ACIVA}

\section{DESENVOLVIMENTO LOCAL,}

AMBIENTE,

ORDENAMENTO

E TECNOLOGIA

Norberto Santos

Lúcio Cunha

COORDENAÇÃO 
Margarida Pereira, Maria Adelaide Carranca

e-Geo - Centro de Estudos de Geografia e Planeamento Regional-FCSH/UNL

\section{COESÃO TERRITORIAL E GOVERNANÇA: ABORDAGEM MULTI-ESCALAR ${ }^{1}$}

\section{ProblematizaÇÃo}

Desde os finais dos anos 80 que a Comissão Europeia, em trabalhos intergovernamentais, estimulou iniciativas para o desenvolvimento de estratégias de ordenamento transnacional do espaço comunitário (Ferráo 2003). Deste processo destaca-se o EDEC (CE 1999), que afirma três elementos fundamentais para o ordenamento do espaço comunitário: o sistema urbano, a rede de transportes e o património natural. Mas os seus objectivos políticos - coesão económica e social, desenvolvimento sustentável e competitividade equilibrada do território europeu - tinham subjacente uma ambiguidade: o foco estava na coesão ou na competitividade do território europeu? (Waterhout e Faludi 2007). O documento introduziu (timidamente) o conceito de coesão territorial, referido no Tratado de Amesterdão (1997). Apesar da sua concretização limitada, influenciou os quadros teóricos e práticos do ordenamento do território em vários EM, nomeadamente através do reforço da dimensão estratégica do planeamento, do quadro de referência para a acção colectiva e da dimensão pró-activa do planeamento, estimulando o envolvimento dos actores e das instituiçóes no processo (Mourato e Rosa Pires 2007, p. 40-41). Em 2004, em Roterdão, as conclusóes da reunião Informal de Ministros da EU responsáveis pelo ordenamento do território referem a coesão territorial como um dos objectivos políticos da cooperação em matéria de ordenamento do território. Mas só a Agenda Territorial Europeia (CE 2007) apontou a coesão territorial como objectivo de política de desenvolvimento da UE. Com a introdução da coesão territorial no Tratado de Lisboa (2007) como terceira dimensão da missão da UE de Coesão Económica e Social e a publicação do Livro Verde sobre a Coesão Territorial Europeia (CE 2008), o conceito foi definitivamente adoptado. Num ambiente global de elevada competitividade, todos os territórios têm de ser competitivos, valorizando os seus recursos e tirando partido da diferença, pois «(...) mais do que compensar ou redistribuir, a política de coesáo precisa (...) de mobilizar todo o potencial de uma regiáo para que esta seja competitiva no plano global» (Covas 2009, p.79).

O conceito, amplo e pouco preciso, está centrado nas seguintes ideias-chave: valorização do capital territorial, apostando nas capacidades produtiva e criativa de cada território; acesso justo e equilibrado aos equipamentos, às infra-estruturas e ao conhecimento; mobilização da

\footnotetext{
${ }^{1}$ No âmbito do Projecto Territorial Cohesion in Portugal: new insights for spatial planning. Financiamento Plurianual FCT.
} 
inovação e do conhecimento, do desenvolvimento tecnológico e do reforço da capacidade de empreendedorismo dos territórios; articulação das intervençóes sectoriais, numa tentativa de fazer prevalecer o interesse do território em detrimento dos interesses sectoriais; policentrismo como conceito de estruturaçáo do sistema urbano, não só porque potencia um modelo económico mais competitivo, favorecido pelas complementaridades e especializações potenciadas pela inserção em rede, como pela distribuição mais equitativa de equipamentos públicos. Para tal é defendida uma acçáo centrada em três princípios nucleares: concentração, conexão e cooperação (CE 2008).

No mundo contemporâneo marcado pela (grande) fragmentação do poder político e uma influência (cada vez mais) determinante dos actores económicos e sociais nas dinâmicas territoriais, as estruturas tradicionais de governação, centralizadas e hierarquizadas, revelam-se incapazes de responder aos desafios apontados. $\mathrm{O}$ termo governança surge para valorizar estruturas de governabilidade descentralizadas, partilhadas por actores públicos e privados. Para além do reforço da cooperação e da coordenação, dimensóes que podemos designar «de substância», a nova abordagem de governança tem que responder igualmente a dois desafios "de forma»: quer a promoção de soluçóes horizontais e verticais no seio da Administração, quer a necessidade de enquadrar o envolvimento da sociedade civil, dando maior consistência e estabilidade aos processos de decisão. A concepçáo de soluçóes de governança criativas coloca-se ainda com mais premência em territórios marginalizados, para os quais são cruciais (mas escasseiam...) investimentos e parceiros promotores de desenvolvimento.

Neste contexto, importa reflectir sobre os dois entendimentos de governança dados por Davoudi et al., (2008, p.351-352) em associaçáo estreita com o conceito de coesão territorial. O território enquanto construçáo política e social é o produto da acção colectiva de grupos de interesses organizados e das instituiçóes territoriais, mobilizados para encontrar uma solução para um problema colectivo, influenciada pela interacção entre os actores em presença. Neste contexto, governança é a capacidade dos actores, públicos e privados, conseguirem um consenso organizacional para definir objectivos e uma visão comum para o futuro desse território, e cooperarem para a sua concretização. A interacção dos actores e dos recursos pode ocorrer a outra(s) escala(s), implicando a redefiniçáo do território de intervenção e, quiçá, das soluçóes. Enquanto capital territorial (associado a características estruturais diversas e ao seu posicionamento geográfico), o território influencia a capacidade de promover e de atrair investimento. A governança é agora entendida como a organização territorial decorrente das relaçóes inerentes à interacção entre actores. Essa visão, ancorada no reconhecimento e valorização do capital territorial, promove a coesão territorial sustentável numa perspectiva multi-escalar, no respeito pelo princípio da subsidariedade.

As potenciais vantagens do binómio coesão territorial/governança têm uma leitura mais fácil às escalas nacionais e regionais, mas é também necessário o seu incremento à escala local.

\section{MÉTOdo E ANÁLISE}

A globalização da economia e o esbatimento das fronteiras nacionais trouxe dados novos ao desenvolvimento: a disputa aguerrida pela captação (e manutenção) de investimento cria 
um ambiente de permanente instabilidade e incerteza aos territórios, muitos sem condiçôes de competitividade e, por isso, marginalizados por esta concorrência (quase) sem regras.

$\mathrm{Na}$ Europa, os sistemas de planeamento são diversos e têm sofrido adaptaçóes (Faludi 2009), procurando respostas mais ajustadas à evolução dos objectivos de desenvolvimento e de ordenamento, para potenciar as sinergias do mercado e contrariar as pressóes territoriais.

Tendo como referência a realidade nacional, e como enquadramento conceptual o exposto sobre a relação coesão territorial/governança, procura-se resposta para duas perguntas: o sistema de planeamento em Portugal potencia, nos seus princípios, objectivos e instrumentos, os requisitos exigidos para a coesão territorial? As estruturas de governança existentes aos diferentes níveis da intervenção pública mostram-se ajustadas aos desafios actuais?

O sistema de gestão territorial em vigor, consagrado pela Lei de Bases da Política de Ordenamento do Território e Urbanismo e pelo Regime Jurídico dos Instrumentos de Gestão Territorial, está balizado pelos princípios da sustentabilidade e solidariedade intergeracional, economia, coordenação, subsidariedade, equidade, participação, responsabilidade, contratualiza-ção e segurança jurídica. Destacam-se como traços fundamentais: estrutura multi-níveis (nacional, regional, municipal); figuras de plano de natureza estratégica, sectorial e regulamentar, associadas a uma morosa tramitação para a sua aprovaçáo e a um sistema de articulação (vinculação, compatibilização) pesado; relevância do Plano e menorização da sua execução.

Para avaliar se o sistema de planeamento consagrado tem capacidade para responder aos desafios da coesão territorial, procede-se à leitura da articulação dos instrumentos de desenvolvimento territorial com os instrumentos de planeamento territorial. Os primeiros, estratégicos, visam capacitar os territórios com uma visão e um modelo de desenvolvimento; os segundos estáo vocacionados para a regulação da transformação do uso solo.

\section{RESUlTADOS}

Nível nacional

O Programa Nacional da Política de Ordenamento do Território (PNPOT) apresenta uma ambição para Portugal num horizonte de longo prazo. Constitui a «(...) Magna Carta em que se tipificam os grandes compromissos do Estado, relativamente ao País (Gente e Território)» (Gaspar 2007, p.86). Representa uma "charneira de mudança» (Mourato e Rosa Pires 2007, p. 41), mostrando um esforço voluntarista de articulação e integração do seu vasto campo de acção: os domínios ambiental, económico, social e cultural; as dimensóes do ordenamento e do desenvolvimento territorial (competitividade, coesão, sustentabilidade, qualidade de vida); os recursos territoriais (recursos e valores naturais, áreas agrícolas e florestais, património, redes de acessibilidades, de infra-estruturas e de equipamentos colectivos, sistema urbano, e localização das actividades económicas) (MAOTDR 2007, p.225).

A elaboração do PNPOT, da responsabilidade do Ministério com a tutela do ordenamento do território, segue os princípios orientadores do EDEC e tem subjacente os pressupostos estruturais do conceito de coesão territorial: policentrismo, identidade, cooperaçáo, articulação. Tem três componentes essenciais: uma Visão, apoiada nas orientaçóes estratégicas para o desenvolvimento do território; um Modelo Territorial, tradução espacial dessa visão; um Programa das Políticas, explicitando os objectivos estratégicos, os objectivos específicos e as medidas prioritárias propostas para a sua execução. O processo de planeamento 
envolveu duas estruturas de participação: Sistemas de Pontos Focais (integrando representantes dos organismos da administração central e regional mais ligados com as políticas de ordenamento do território) e Comissão Consultiva (instituiçóes da sociedade civil, relevantes para o processo), tendo o esforço de convergência (das abordagens sectoriais) sido notório e notável, viabilizando a sua aprovação.

A operacionalização do PNPOT acontece pela confluência de intervençóes públicas repartidas por oito áreas de acçáo governativa: legislação; estratégia, planeamento, regulação; informação, coordenação, avaliação; administração, execução, incentivo, destacandose esta última (MAOTDR 2007,p. 236). As intervençôes mais visíveis estão associadas às políticas sectoriais com incidência territorial, à territorialização das orientaçóes estratégicas nacionais e sua adaptação às especificidades regionais através dos PROT e ao planeamento territorial (orientaçóes para os PMOT).

A avaliação empírica da sua curta aplicação (2007-2009) permite constatar o confronto de lógicas nem sempre convergentes: do ordenamento, do desenvolvimento e sectoriais. Alguns avanços foram conseguidos: elaboração dos PROT (dois concluídos, os restantes em finalização), avanço do SNIG e do SNIT. Mas os sinais de dificuldades são já reveladores: cada sector permanece muito agarrado à «sua» racionalidade, manifestando pouca (nenhuma...) abertura para uma integraçáo com outros sectores; as políticas sectoriais continuam a ser gizadas à margem da dimensão territorial e o confronto entre equidade e eficácia é particularmente visível nas políticas associadas à prestação de serviços públicos (embora com tradução espacial distinta em territórios fortemente urbanizados e de muito baixa densidade), a entidade responsável pela sua elaboração «apagou-se» e persiste a ausência de uma entidade com poder (efectivo) para arbitrar conflitos de interesses ou contradiçóes sectoriais no seio da Administração, perante a evidente incapacidade de articulação horizontal intersectorial - o Conselho de Ministros é a única instância para a harmonização formal de políticas, mas sem vocação para a concertaçáo técnica; atraso na criação do Observatório do Ordenamento do Território e do Urbanismo, o que inviabiliza a produção de informação operacional e a avaliação dos resultados (não) alcançados.

\section{Nível regional}

A elaboração dos Planos Regionais de Ordenamento do Território (PROT) compete também à Administração Central, através das Comissóes de Coordenação e Desenvolvimento Regional (CCDR $)^{2}$, estruturas desconcentradas do ministério com a tutela do ordenamento do território. O PROT constitui o instrumento estratégico de charneira entre as escalas nacional e municipal. Pilar da política de desenvolvimento territorial, cabe-lhe detalhar as orientaçôes consagradas ao nível superior e adaptá-las às especificidades regionais e subregionais. A orientação metodológica comum, por determinação da SEOTC (2005) procurava harmonizar as abordagens e facilitar a integração.

Os PROT formulam a Visão estratégica (ambição de desenvolvimento a longo prazo) e as Opçóes Estratégicas de Base Territorial (linhas de intervenção das políticas com incidência territorial - utilização de recursos territoriais, ocupação, uso transformação do solo

\footnotetext{
${ }^{2}$ Com excepção das Regiōes Autónomas dos Açores e da Madeira.
} 
e localização de actividades, equipamentos e infra-estruturas), diferenciando os Eixos Estratégicos (territorialização das opçóes de desenvolvimento e intervençóes para os principais sistemas com expressáo territorial) e o Modelo Territorial (referência espacial para a concretizaçáo dos objectivos estratégicos de desenvolvimento, incluindo a estrutura geral de organização do território, os componentes do modelo e suas relaçóes e os espaços sub-regionais mais relevantes, para os quais são apontadas estratégias específicas de intervenção. O Programa de Acção tem carácter indicativo.

A análise de alguns PROT comprova que dão seguimento às orientaçóes nacionais, ajustando-as aos constrangimentos e potencialidades regionais/sub-regionais, mas também sobressai uma tendência para a exaustividade das propostas, com prejuízo de uma selectividade das opçóes. De facto, num contexto de escassez de investimento (público e privado), é benéfico explicitar as apostas prioritárias, o que tem de ser feito (verdadeiramente estratégico), sob pena de a visão traçada ficar comprometida (atomização das intervençôes, com resultados aquém dos recursos consumidos). Esta linha de rumo tem de ser inequívoca para todos os intervenientes no processo de desenvolvimento. A par, devem ser apontadas as combinaçôes virtuosas (geradoras de sinergias) e as associaçôes maléficas (susceptíveis de provocar efeitos contrários ao desejado). Também a este nível o esforço de concertação foi intenso e nem sempre fácil, sobretudo o ligado às políticas sectoriais.

Apesar do inegável mérito do processo de planeamento dos PROT, a sua operacionalizaçáo apresenta grande fragilidade, dado acontecer sobretudo por via da coordenação das políticas sectoriais à escala regional e da transposição da normativa para a escala municipal. A avaliação empírica da sua aplicação permite detectar (e/ou antever) debilidades diversas. A dificuldade (política) de coordenação das políticas sectoriais por parte das CCDR é indisfarçável: a lei orgânica das CCDR (2007) criou o Conselho Intersectorial de Coordenaçáo, ainda não operacionalizado. Mas, mesmo que tal acontecesse, a aplicação regional das políticas públicas não passa pelos responsáveis pelos departamentos desconcentrados (quando existentes) e a capacidade efectiva de coordenaçáo das CCDR é diminuta (aqueles estão vinculados à sua estrutura central). Este aspecto é agravado pela não responsabilização dos departamentos centrais sobre os compromissos (assumidos durante a elaboraçáa) relativos à concretização das suas políticas (execução, calendarização, priorizaçáo). Esta prática (comum...) pode comprometer as estratégias regionais, sem que as CCDR tenham poder efectivo para inverter a situação. A concertação com as autarquias também nem sempre é fácil, havendo expectativas sobre o modo como as revisóes dos planos municipais vão acolher a normativa que lhes é aplicável. $\mathrm{Na}$ actual estrutura governativa, a dupla tutela que se prevê para as CCDR (Ministério do Ambiente e Ordenamento do Território e Ministério da Economia) pode vir agravar (ainda mais) a articulaçáo das acçóes de desenvolvimento com as de ordenamento. Aliás, a instabilidade na estrutura e no papel das CCDR (verificada ao longo dos anos, por força das mudanças das orgânicas governamentais) é particularmente nociva para o desempenho das suas atribuiçóes.

Assim, a estratégia regional pode ser comprometida (no extremo inviabilizada) por falta de concertação entre actores públicos. Este contexto de desarticulação fragiliza a ambição de criar uma plataforma de diálogo, concertação e debate, integrando os actores económicos e sociais, requisito indispensável ao seu envolvimento efectivo na prossecução do desenvolvimento ambicionado, no sentido do reforço da coesão territorial e da garantia de equidade para pessoas, empresas e instituiçóes, independentemente do contexto geográfico de inserção. 


\section{Nível municipal}

Os municípios são cruciais na política de ordenamento do território, já que a essa escala se materializa o licenciamento da urbanizaçáo e da construçáo. Os planos regionais surgem quando está em curso a revisão da maior parte dos Planos Directores Municipais (PDM). Esta coincidência revela-se virtuosa, pois estes darão acolhimento e sequência às orientaçóes daí emanadas. Está, assim, criado um contexto muito diferente do dominante na primeira geração de PDM, sem enquadramento estratégico de nível superior. Esta limitação marcou os documentos entáo produzidos: instrumentos descritivos e regulamentares das ocupaçóes existentes, sem uma visão optimizada dos recursos locais; modelos de ordenamento padronizando as soluçóes, pouco criativos e adaptados às especificidades locais e nem sempre apostados na valorização das identidades, sobretudo direccionados para a infra-estruturaçáo e equipamento do território e para a definiçáo de regras urbanísticas; debilidade das orientaçóes para o desenvolvimento da base económica; burocratização e ineficácia da gestão municipal, penalizando a competitividade dos territórios; cooperação intermunicipal residual.

A segunda geração de PDM surge num contexto económico, político e social muito diferente: o território sofreu alteraçóes estruturais, nas formas de organização, nas dinâmicas instaladas e nos actores envolvidos; a capacidade de controlo das transformaçóes é cada vez mais limitada e os desafios contemporâneos (de competitividade, de sustentabilidade e de equidade) são mais exigentes e de alcance mais difícil do que a infra-estruturação básica; o actual enquadramento do PDM enfatiza o seu carácter estratégico, devendo explicitar a visão do município sobre o que deve ser o seu desenvolvimento e o modo de o concretizar; a alteração do seu processo de aprovação (agora da competência da assembleia municipal), ao reforçar a autonomia municipal segundo o princípio da subsidariedade, responsabiliza mais os eleitos locais.

A existência de uma estratégia de desenvolvimento para a região e sub-regióes permite aos municípios uma leitura dos seus territórios já não como «ilhas» mas como parte integrante de uma unidade geográfica mais alargada, onde têm um papel a desempenhar, estimulando actuaçóes conjuntas e concertadas, pois as dificuldades do presente aconselham (exigem) acçóes colectivas. Se as administraçóes locais estão focalizadas nos territórios que as elegeram, o governo local terá de ajustar-se aos novos objectivos e às condiçóes de recursos cada vez mais escassos: muitas das acçóes beneficiam de cooperação territorial de dimensão inter-municipal (nuns casos para conseguir massa crítica, noutros para combater deseconomias da concentraçáo), para rentabilizar (partilhar) recursos e assegurar as melhores condiçóes de serviços às populaçóes (a Lei do Associativismo Municipal vai nesse sentido ${ }^{3}$ ). Esta nova forma de actuação exige a clarificação de uma linha de rumo para o município e mudanças organizacionais internas.

O reforço da visão estratégica dos PDM é imperativo. Porém, esta condição pode estar em risco, devido à acumulação de directrizes sectoriais que esta figura de plano está forçada a integrar. Mas outra mudança se impóe: a gestáo municipal tem que perder o seu carácter reactivo e a sua focagem excessiva no processo de transformaçáo do uso do solo para assumir uma atitude pró-activa, de mobilização e de concertação das acçôes que con-

\footnotetext{
${ }^{3}$ Lei no 45/2008, de 27 de Agosto.
} 
correm para a transformação do seu território, em particular as associadas à geração de riqueza a partir dos recursos endógenos. Com desafios territoriais cuja dimensáo global escapa à capacidade de intervençáo, as formas mais adequadas das autarquias gerirem a incerteza e os impactes socioeconómicos e territoriais subsequentes passa pela cooperaçáo territorial, valorização do seu capital territorial e consolidação de parcerias estratégicas.

\section{CONTRIBUTOS PARA AS POLÍTICAS PÚBLICAS}

Como se procurou demonstrar, os princípios da Coesão Territorial marcam os modelos de desenvolvimento propostos às escalas nacional e regional. E espera-se que a formalização da revisão dos PDM concorra para operacionalizar aquelas orientaçóes.

Mas as debilidades relativas à governança, evidentes a todos os níveis, podem ameaçar aqueles propósitos, pelo que é indispensável combater tais limitaçóes. Assim é necessário responsabilizar cada área de administração sectorial do Estado a compatibilizar as suas propostas e prioridades com o PNPOT e criar uma plataforma de concertação técnica de políticas ao nível central, indispensável para dirimir conflitos e construir compromissos colectivos. Do mesmo modo é preciso dotar as CCDR de efectivos poderes de coordenação para ultrapassar as contradiçóes sectoriais à escala regional, reforçar a sua articulação com as autarquias locais e serem reconhecidas pelos actores económicos e sociais como interlocutoras essenciais na promoção/apoio de iniciativas de investimento. Ao nível local três acçóes parecem prioritárias: a simplificação do conteúdo do PDM, tornando-o mais estratégico, isto é, clarificador das opçốes de desenvolvimento e dos caminhos para as atingir; o estímulo à cooperação intermunicipal como forma de gerir melhor os recursos escassos; e a mobilização das autarquias para uma gestão pró-activa, criando estruturas de envolvimento efectivo dos actores locais como incubadoras de parcerias estratégicas, pilares do desenvolvimento a perseguir. Esta convergência de acçóes, em redor de um projecto territorial colectivo, reconhecido e assumido, permite às autarquias gerir melhor as incertezas globais que afectam os seus territórios e acautelar/minorar impactes territoriais resultantes de decisóes que escapam à sua capacidade de intervenção.

\section{REFERÊNCIAS BIBLIOGRÁFICAS}

CE 2008, Livro Verde Sobre a Coesão Territorial Europeia: Tirar Partido da Diversidade Territorial, COM(2008) 616 final, Bruxelas; de http://ec.europa.eu/regional_policy/consultation/terco/paper_terco_pt.pdf.

CE 2007, Agenda Territorial da Uniäo Europeia; DGOTDU, Lisboa.

CE - Commission of the Europen Comunities 2001, European Governance - A White Paper, Brussels 25.7.2001, COM (2001) 428 final.

CE 1999, European Spatial Development Perspective: Towards balanced and sustainable development of the territory of the European Union; de http://ec.europa.eu/regional_policy/sources/docoffic/official/reports/pdf/ /sum_en.pdf.

Covas, António 2009 Integração Europeia, Relações Ibéricas e Política de Regionalização, Edições Colibri, Lisboa.

Davoudi, S.; Evans, N.; Governa; F.; Santangelo, M. 2008, "Territorial Governance in the Making. Approaches, Methodologies, Practices”, Boletín de la A.G.E. n. ${ }^{\circ}$ 46, pp.351-355

Faludi, Andreas 2009 Progress in Planning: A turning point in the development of European spatial planning? The 'Territorial Agenda of the European Union' and the 'First Action Programme'; Delft University of Technology, OTB Research Institute for Housing, Urban and Mobility Studies, Delft, The Netherlands. 
Ferrão, João 2003 “A emergência de estratégias transnacionais de ordenamento do território na União Europeia: reimaginar o espaço europeu para criar novas formas de governança territorial?, GeoINova - Revista do Departamento de Geografia e Planeamento Regional, no 7, FCSH, Lisboa, p. 11-37.

Gaspar, Jorge 2007 "Notas em torno do processo de elaboração do PNPOT“, Sociedade e Território, no 40, Fevereiro, pp.74-86.

MCOTA 2007, Programa Nacional da Política de Ordenamento do Território, MCOTA, Lisboa.

Mourato, João; Rosa Pires, A. 2007, "Portugal e a perspectiva de desenvolvimento do espaço Europeu: o EDEC como institucionalização de um discurso de mudança”, Sociedade e Território, no 40, Fevereiro, pp.34-42.

SEOTC 2005, PROT 2006: Orientaçóes para a elaboração dos Planos Regionais de Ordenamento do Território; de www.ccdrc.pt/prot/prot2006.pdf.

Waterhout, Bas; Faludi, Andreas 2007, "The Emerging EU Territorial Cohesion Agenda: the Ball in the Court Of the Member states", Sociedade e Território, no 40, Fevereiro, pp.12-19. 